\title{
Editorial: Pathways towards sustainable landscapes
}

\author{
Iris C. Bohnet • Ruth Beilin
}

Published online: 24 February 2015

(C) Springer Japan 2015

Keywords Holistic · Approach · Governance · Social-ecological $\cdot$ Sustainability

\section{Introduction}

Researchers and practitioners with an interest in a holistic conception of landscape argue for more deliberate approaches to plan, develop and manage landscapes (e.g. Beilin et al. 2012; Bohnet 2008; Dramstad and Fjellstad 2011, 2013; Musacchio 2009, 2013; Pearson and McAlpine 2010; Potschin and Haines-Young 2006; Tress et al. 2003; $\mathrm{Wu}$ 2013). These scholars argue that in order for landscapes to be considered sustainable they must fulfil multiple functions and values, including the provision of healthy food, clean water, fresh air, livelihoods and recreational opportunities, productive and healthy ecosystems, as well as reflecting on aesthetic and cultural values.

To date, landscape theory and practice has advanced the possibilities with its focus on the development of new paradigms, conceptual frameworks, new governance models, and tools and processes on how to effectively engage with multiple stakeholders. These are intended to

I. C. Bohnet

CSIRO, Land and Water Flagship, Cairns, Australia

I. C. Bohnet $(\bowtie)$

Centre for Tropical Environmental and Sustainability Science, James Cook University, Cairns, Australia

e-mail: iris.bohnet@jcu.edu.au

R. Beilin

Landscape and Environmental Sociology, Faculty of Science, University of Melbourne, Melbourne, Australia

e-mail: rbeilin@unimelb.edu.au improve discussions about potential trade-offs between competing landscape values, effects of land use and management changes, and decisions about future landscapes (e.g. Beilin et al. 2012, 2013, 2014; Bohnet and Smith 2007; Bohnet 2010; Bohnet et al. 2010, 2011a, b; Angelstam et al. 2013; Kasemir et al. 2003; Sayer et al. 2013; Van Paassen et al. 2011). However, recognition of new paradigms, complex decision frameworks and models is just a first step in the dynamic reality that is the quest for sustainable living and species survival. As an example, we can integrate food production regimes within vastly more polycultural landscapes and achieve conservation goals without sequestering land in isolation from food systems if we recognise the need to constantly negotiate the meaning and character of sustainability (Estrada-Carmona et al. 2014; Milder et al. 2014; Scherr and McNeely 2008).

This special issue in sustainability science originated in the collaboration between the two guest-editors. We are landscape scholars and research practitioners. We work across multiple disciplines to gain a better understanding of the complex dynamics that arise from interactions between multi-scalar social and ecological systems, i.e. landscapes, to inform theory and practice. With the idea in mind that farming and the production of food present key challenges in most landscapes, we organised a session on sustainable landscapes at the Agri-Food XX 2013 resistance, resilience and security conference, held at the University of Melbourne from 2 to 5 December 2013. Six papers in this special issue were presented at that organised session. All other papers were from the open call for papers on the journal's webpage or invited contributions.

We have been building this special issue with a tacit or explicit recognition that the sixteenth century concept of 'landskip' itself has always provided a 'view' that intended to be inclusive, and tie the visible elements of that view 
together in order that the viewer could make sense of what was seen. Now in the twenty-first century, sustainability science offers a metaphor for a holistic approach to sustainability itself. The landscape is indeed dynamic and, extending the 'view' allows us to focus on the background and the foreground, integrating these into the social construction of what is seen. Importantly, with a socio-ecological view-one that is heavily discussed in this issuewe can extend the 'knowing' to what is not seen-what lies beneath the view. In this way, management of the terrestrial zone includes land, water, soils and the production of consequent elements.

The authors in this special issue continue a tradition of broad scholarship within landscape research, presenting multiple views and tools to define its sustainability. They harness function, ethics and ideals and point to the successes and failures of governance and government (e.g. Beilin and Bohnet 2015), local and regional triumphs (e.g. Hunt 2014) and global and local impediments (e.g. Christensen and Gaire 2014; Clapp 2014; Hill et al. 2015). This special issue represents a work-in-progress as we recognise that the 'landscape' metaphor is intrinsically about people in places at a time when the Earth is frequently conceived as global and 'placeless'. To counter this tension requires our fostering of sustainability science (and practice), and defining of resilience as dynamic; and depending on the ability of society as a whole, to encourage the adaptation necessary for ongoing critical transformation that begins now.

Using landscape (Fig. 1; Swanwick and Consultants 2002), framed as social-ecological system (Folke 2006), as a lens (e.g. Beilin and Bohnet 2015), scale (e.g. Clapp 2014), and point of departure (e.g. Christensen and Gaire 2014; Hunt 2014; Santhanam-Martin et al. 2014), the papers in this special issue study practical sustainability challenges in real-world human development systems. The contributions are as diverse as the landscapes under investigation and written by a wide range of scholars from the social and natural sciences as well as the humanities. Many of the authors are agri-food scholars with backgrounds in agriculture, sociology, economics, law, and international relations. Some authors' scholarly research is applied to the problems of reconciling biodiversity conservation and development in tropical and frontier landscapes. Their backgrounds are in conservation planning, development practise, governance systems, and anthropology.

The majority of the papers are based on empirical research undertaken in particular places-in landscapes that people live and work in, and care about-and address pressing real-world sustainability issues. Others respond to practical sustainability challenges that cut across and
Fig. 1 The concept of landscape, resulting from the way different natural, cultural, social, perceptual and aesthetic components interact and are perceived by people (Swanwick and Consultants 2002)

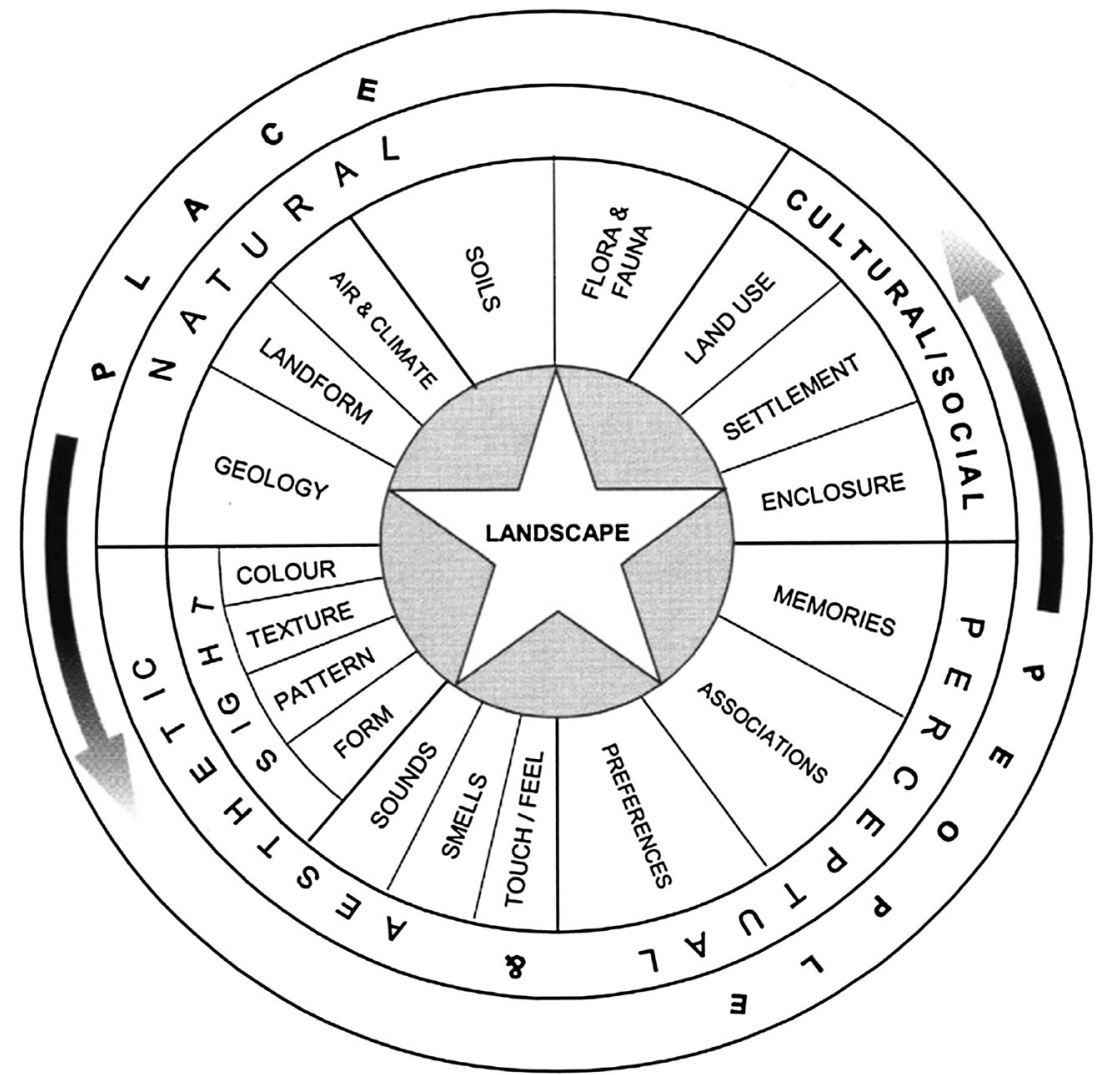


impact upon landscapes in diverse ways. These latter papers deal with, for example, the global use of pesticides in agricultural production systems (Parker 2014) and the effects of the global industrial food system on agricultural landscapes (Clapp 2014). The case study landscapes cover many countries around the world including New Zealand, Australia, Indonesia, Japan, Nepal, Cameroon, Congo, Central African Republic and Germany. They include old (in the sense of traditional) and new (as in new frontier) landscapes, and landscapes undergoing major transformations. However, a feature common across all landscapes is change.

\section{Overview of papers in this special issue}

The first set of papers presents case studies from particular landscapes around the world that address real-world sustainability challenges in a place-based and historical context. These case studies provide examples of how local and other actions across scales and levels of governance have or have not contributed towards creating pathways for sustainable landscapes. The second set of papers deals with sustainability challenges that are not place-specific but cut across and impact upon landscapes in diverse ways. These latter papers illustrate that the sustainability challenges described are primarily driven by global, economic and market forces and are highly influenced by public discourses and framings. These papers point to the need for action at multiple levels of governance and in changes to the way public discourses, particularly around food, are framed. Most importantly, they point to the need for these global, economic and market forces to be contextualised in order to improve landscape outcomes.

Seen together, the sum of the stories and arguments presented in the papers of this special issue are pointing to the need for local people and nations to define sustainable landscapes as part of their nation's goals. These sustainable landscapes, as suggested in several contributions, need to be founded on social justice, limited resource use and a renewed ecological sensibility and cultural awareness that society has long been ignoring.

Sustainability challenges and learnings explored through case studies

Building on the concept of landscape (Fig. 1), Beilin and Bohnet (2015) derive a conceptual framing of the 'landscapes of somewhere', pointing to the importance of culture, production and place in developing pathways towards sustainable landscapes. The paper presents an analysis of three landscape management experiences in Australia. The authors argue that invoking the social-ecological imaginary as a change agent in the creation of sustainable landscapes challenges the civic discourse about how the 'landscapes of somewhere' evolve. Further, culture-production-place underpins how we engage with nature, in the social construction and the longer-term social responsibility for landscape as a social-ecological interface.

The next two papers explore the challenges within agricultural production landscapes as local people search to define and improve their sustainability through their relationship with place. The paper by Santhanam-Martin et al. (2014) uses 'community sustainability' as the conceptual entry point. The paper explores how landscape development trajectories result from discursive place-frames that draw on different sets of place-making relations. The results suggest that agricultural landscape change towards sustainability, as broadly understood by sustainability scholars, is likely to be an incremental process. This process appears to be shaped by past experiences and builds on existing physical, social and economic relations in these locations.

The paper by Hunt (2014) analyses what individual farmers actually do; their farming practices and outcomes of those practices, some if which are visible in the landscape. This analysis is based on the collection of data from New Zealand family farms over a period of 8 years. The results reveal five different pathways that farmers have taken over this time. To continue farming through the recent difficult years of increasing costs and financial uncertainty, farmers have chosen a mix of diverse possibilities available to them. The paper illustrates how change is more likely to emerge from what farmers 'know' already, which is in line with the previous paper (SanthanamMartin et al. 2014). Importantly, it also links policy outcomes to on-farm decisions, indicating that policy intentions are frequently subverted by on-ground realities. This has ramifications for policy and governance as rapid environmental change may not permit the lead time that farmers have associated with decision-making and maladaptation may result (Beilin et al. 2013).

The next three case study papers explore, through different points of departures, how pathways towards sustainable landscapes can be established. The paper by Fielke and Bardsley (2014) starts with an historical analysis of agricultural policy in Australia to study the regional disparity and its implications for agricultural sustainability in peri-urban and rural South Australia. The results from their study highlight the complexity involved with applying appropriate government support mechanism across a diverse industry such as agriculture. This echoes the finding from the previous paper by Hunt (2014). Fielke and Bardsley (2014) suggest that regional variation requires explicit planning for heterogeneous goals, and educational and cooperative pursuits may help to build land mangers' 
capacity to improve landscape sustainability. Again, the challenge here is how to use policy tools to create connectivity between the various sites of change-i.e. the establishment of networks to assist with social learning and social cohesion-without inhibiting creativity and innovation that is frequently site specific. Such networks can overcome the limitations of distance if the scale of operation is supported by, for example, dependable internet platforms, but others, as in the German example (Bohnet and Konold 2015), may take their boundaries from historic regional frames.

Bohnet and Konold (2015) critically reflect on the conventional nature conservation and spatial planning instruments available in Germany's southwest. The authors explore the potential of new boundary organisations that have been established to govern and manage cultural landscapes more sustainably. Although no panacea, the authors argue that regional development strategies-if developed from bottom to up and governed by new boundary organisations-are likely to support management and development of cultural landscapes more effectively than the application of the conventional instruments on their own.

Applying the ecosystem services framework in the Noto Peninsula, a globally important agricultural heritage system in Japan, Hashimoto et al. (2014) map and characterise ecosystem services to build a scientific basis for conservation and development planning. The authors suggest that their detailed analysis and evaluation of the spatial variation, types and abundance in ecosystem services could be used as a starting point for further explorations. For example, to study locales that may be undervalued by the public, even if the location is historically or scientifically important. In this regard, the generated maps could be used to explore locales that need special care and improved public understanding of its combined ecosystem service values.

Sustainability challenges and learnings explored through themes cutting across landscapes

The first two papers use a crop-apples and strawberries-as their lens to look at global interdependencies, i.e. pervasive economic pressures that homogenise expectations of how to grow agricultural commodities. With their narratives of apple growing, Christensen and Gaire (2014) establish a deep understanding of sustainable landscapes by contextualising and comparing two agricultural landscapes, one in Nepal and one in Australia, in which apple growing is promoted by government programs. The results suggest that identity and place play an important role in the way growers interact with their local landscapes. The authors argue that with each change in scale of production, sustainability is redefined and ways of operating re-imagined. However, the push to be part of national (in the Nepali case) and global (in the Australian) production systems has not improved local peoples' ability to sustain their way of life. Rather, the paper suggests that the ecological well-being of both locations has been secondary to the market imperative and while immediate income may increase, only some growers can continue to participate over time, in both locations.

Using strawberries-a highly pesticide-intensive cropas a lens, Parker (2014) addresses the issue of pervasive and intensive use of pesticides in agricultural production systems. The paper tracks back how consumption choices are framed by regulatory choices in which consumers have little engagement. The results highlight the limits of consumer choice as a method of deliberative democratic engagement with issues of agri-food sustainability. It also points to the importance of international connections, as in the Christensen and Gaire (2014) paper, where analysis of pesticide use, or crop developments in one nation, is frequently repeated, sometime later, in another.

The paper by Clapp (2014) that follows explains that the global economic drivers are hidden not just by time, as above, but, importantly, by 'distance'. By examining the relationship between the development of the dominant industrial food systems and its associated global economic drivers, Clapp (2014) traces back the growing distance in the dominant food system in the past century. The author argues that the growth of the global industrial food system has encouraged increasingly complex forms of 'distance' that separate food, both geographically and mentally, from the landscapes on which it is produced. This separation between food and its originating landscape poses major challenges and complicates efforts to scale up small-scale local agricultural models that are more sustainable.

Carolan (2014) goes one step further. He argues that this globalisation is not just about where agricultural products come from (Beilin and Bohnet 2015), how they are produced (Parker 2014) or the distance to markets (Clapp 2014) but about the agro-industrial complex' ability to create tastes and desires for 'unreal' foods. This industrial production of taste is not related to the food that comes from real farms such as the Nepali apple orchards (Christensen and Gaire 2014) or the beef and sheep farms in New Zealand (Hunt 2014). His examples point to the insidious ways in which food tastes are created and how they become 'part' of the consumers' expectations of what food should look and taste like. Carolan (2014) inherently challenges us to 'know' what we eat. At some levels, this aligns with Beilin and Bohnet's (2015) assertion of the importance of food being from 'somewhere' in a social-ecological sense. However, as with other papers in this issue, the way sustainability is defined limits the ability to imagine alternative ways to carry out and embody change. Many scholars may argue that to 'feed the world' industrial agriculture 
and industrial food production systems are required. In their definitions of efficiency, these are the most sustainable regimes (Foley 2011). Carolan (2014) argues that we need to think about how the argument about economic sustainability opens the door for consumption that is dependent on the same markets for its social sustainability.

Marsden and Farioli (2015) emphasise the need for synergies among nation-state goals of sustainability, security and sovereignty in order to effect and improve natural resource governance. They also add an economic dimension to sustainable place-making. The authors argue that a transition from the bio-economy to the eco-economy depends on such synergies being part of policy. This transition is important, because the bio-economy framing treats space and nature as a 'vehicle' to be manipulated, without accounting for its ecological and socio-cultural diversity. Whereas framing the argument through an ecoeconomy perspective centralises place and emphasises its ecological diversity as an embedded and critical set of factors in shaping co-produced sustainable transitions.

The paper by Sayer et al. (2014) proposes 10 pre-conditions for the successful application of landscape approaches to derive pathways to sustainable landscapes. These pre-conditions go beyond the technical principles identified in previous studies (e.g. Fischer et al. 2006; Lindenmayer et al. 2008; Sayer et al. 2013) and include: (1) inspired leadership, (2) long-term adaptive commitment, (3) facilitated stakeholder involvement, (4) motivated engagement, (5) openly addressed conflict management, (6) strong systemic governance, (7) private sector engagement, (8) policies supported by budgets for implementation, (9) formalisation and monitoring of process outcomes, and (10) metrics development to establish values, track progress and enable adaptive management. The new boundary organisations established to govern, manage and develop cultural landscapes in Germany more sustainably align with and aspire to meet similar pre-conditions (Bohnet and Konold 2015).

To explore the apparent paradox of biodiversity decline despite protected areas expansion, Hill et al. (2015) developed a simple stock-and-flow model. Using plausible scenarios that depict biodiversity change over time under different governance regimes and land-use trajectories, the authors derive two key insights from their deliberations. First, the forces that drive forest clearance for development do not necessarily oppose those that drive forest protection. Second, the power of the governance regimes that protect existing forest can be weakened by protected area expansion, through appeasing public concern about risks from biodiversity loss, while the power of governance regimes for development concurrently remain strong. The authors recommend further work on the influence of public discourses on biodiversity outcomes.

\section{Concluding reflections}

The case study papers as well as the theme and overview papers in this special issue present theory, process and practice. Two key ideas emerge as critical to achieving pathways to sustainable landscapes. These are, the importance of conceptualising sustainability and of scale, since, as highlighted in many of the contributions, economic development and growth (without considerations of place) still is the overriding force, at least at global and national scales. Secondly, they point to the need for civic discourses to reaffirm 'food from somewhere', 'landscapes from somewhere' and the quest for future sustainability to begin now. Sustainability science will be critical in shaping pathways towards sustainable landscapes, in particular its transdisciplinary research, that supports science and society to engage in and shape these civic discourses (Lang et al. 2012).

The importance of conceptualising sustainability and of scale

Since 'our common future' was published in 1987 (WCED 1987), sustainable development has received increased attention in the business world, political arenas and academia. Sustainable development, as defined in 'our common future' is: 'development that meets the needs of the present without compromising the ability of future generations to meet their own needs' (ibid p. 43. This definition, while popular (especially to the North), is open to different and incompatible interpretations.

Therefore, it is not surprising that almost 30 years later, and despite many efforts at all scales, from global to local, humanity continues on a trajectory that is fragmented and where there are examples of creating a more sustainable and just future there are also many that are not (e.g. Millennium Ecosystem Assessment 2005). To address this widening gap between our current unsustainable development trajectory, some scholars (e.g. Fischer et al. 2007) argue that meaningful sustainability targets need to be part of a new model of sustainability, one that is based on a hierarchical conceptualisation of ecological, social and economic considerations (Fig. 2).

Critical to this hierarchical conceptualisation is the recognition that while trade-offs between the different spheres are possible, the need to maintain the Earth's life support systems puts limits on these trade-offs. Defining sustainability and contributing to sustainability efforts therefore requires a focus on coupled social-ecological systems, e.g. landscapes-their socio-ecological imaginaries. These systems are nonlinear, emergent and counter hierarchy and 'command and control' (Capra and 


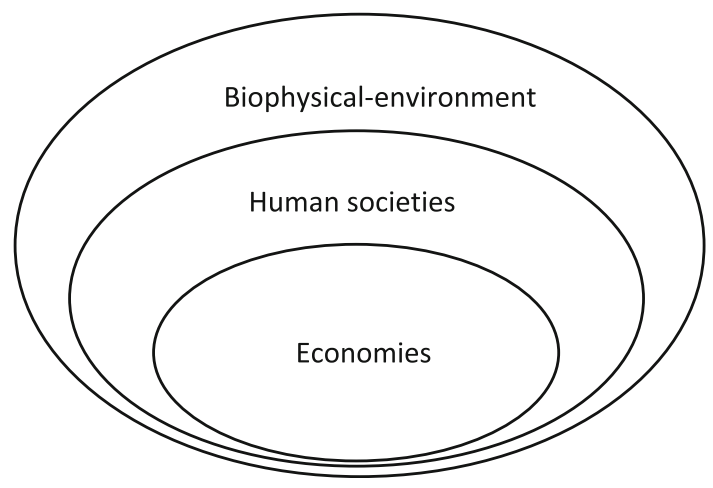

Fig. 2 Conceptualisation of 'strong' sustainability. Social and economic actions are constrained by the biophysical limits to sustaining life on Earth. In other words, the need to maintain a functioning life support system, i.e. the biophysical environment, is paramount for human societies and their economies to thrive. This nested hierarchy conceptualisation of sustainability is in contrast to the notion of 'triple bottom line sustainability' which considers the three pillars (environment, economy, and society) as parallel concepts (Source: modified from $\mathrm{Wu} 2013$ )

Luisi 2014). They provide an understanding of the complex dynamics that arise from interactions between social systems, ecological systems and social change processes (Miller 2013).

Several of the articles in this special issue analyse the sustainability challenges that farmers, as individual land managers and at the farm scale, face (Christensen and Gaire 2014; Fielke and Bardsley 2014; Hunt 2014; Santhanam-Martin et al. 2014) and how they respond to increasing pressures by narrowly framed policies that equate agricultural sustainability with economic productivity, e.g. producing more agricultural products for export and thereby increasing their contributions to the national economy. At a global scale perspective, the articles by Clapp (2014) and Parker (2014) examine the relationship between the dominant industrial food production system and its associated global drivers and the sustainability of agricultural landscapes and products. These articles suggest that the continuing emphasis on economic sustainability instead of a hierarchical conceptualisation of sustainability (Fig. 2) in national and international policies may be one of the root causes to the persisting sustainability challenges society is facing. Similarly, Hill et al. (2015) argue that the emphasis of profit making in public discourse leads to perverse biodiversity outcomes. As a way forward, Marsden and Farioli (2015) suggest a new framing and focus away from the bio-economy to the eco-economy in which place is central.

Despite the global economic drivers, land managers make decisions on their farms-which impact upon their farm landscapes - that are not solely based on rational economic decisions. Similarly, consumers of agricultural products are not 'unfeeling rational actor(s)' (Carolan 2014 $\mathrm{p} \mathrm{x}$ ) and farming decisions as well as consumer decisions are based on a multitude of values, beliefs and assumptions.

The mismatch of spatial and temporal scales, i.e. where and when decisions are made and the time lags between decisions, actions and outcomes, and levels of governance, from individual farms to global policies and regulations, have been identified to provide key challenges and major reasons for unsustainable land-use decisions (Dramstad and Fjellstad 2013). Considering multiple scales, time frames, levels of governance and diversity of decision-makers-at the same time-is critical to avoid perverse outcomes (Beilin et al. 2012). However, we suggest there is merit in using landscape, as a common ground for science and society, to overcome the mismatches between (inter) national aims of sustainable development and actual outcomes on the ground, in a particular place.

Transdisciplinary research for changing human behaviour towards sustainable landscapes

Landscapes, framed as social-ecological systems, where human activities are visible in the biophysical environment and integrated in environmental processes, provide the ideal medium and methods for landscape researchers to synthesise landscape change (Nassauer 2012). Synthesising change at a scale - the landscape scale - that people and society can relate to appears to be at the heart of sustainability (Pedroli 2000; Wascher 2000) and sustainability science (Miller et al. 2014). Also, the concept of landscapes, as spatial reference units, representing the dynamic interactions and changing relationships between people and place and culture and nature, supports bridging the human, social and natural sciences (Tress et al. 2001) and promoting integration and cooperation (Kauffman and Arico 2014).

Landscapes are the setting for people's day-to-day activities and result from the way that different natural, cultural, social, perceptual and aesthetic components, such as geology, soils, climate, flora, fauna, land use, settlement, religion, memory, mentality, sounds, smells, colours, patterns and form, interact and are perceived by people (Fig. 1; Swanwick and Consultants 2002). The outcome of these synergies creates dynamic and evolving landscapes, which are consequently multifunctional and best understood contextually and historically (Antrop 2005, 2006; Beilin and Bohnet 2015; Bohnet and Konold 2015; Christensen and Gaire 2014; Hashimoto et al. 2014; Sayer et al. 2014). We argue that sustainability science, as a growing field of inquiry, offers important insights into the tremendous challenges that researchers face who are committed to act as catalysts for changing societal values that support pathways towards sustainable landscapes. 
Sustainability science is concerned with the using up of finite resources, with the anthropocene and the consequences for the future, and the articles in this special issue lead us to point out that the future begins now-is made out of the present as Schaar (1981, p 321) points out: "The paths [to the future] are not to be found, but made." Indeed, as demonstrated in these papers, they are being made now. Imagining sustainability as a destination will not work, it requires practice, and people talking and working together, trying out new things and feeling new experiences (Carolan 2013, 2014). What is sustainable today will be understood differently in 10 years - that is the history of the wet tropics and of the landcare plantings (Beilin and Bohnet 2015). We cannot wait for everything to be aligned or all pre-conditions to be met (Sayer et al. 2014), for symmetry across all landscapes. Each place and its context will be socially and ecologically different. We can have some guidelines or landscape targets to be met, such as $30 \%$ of all production landscapes must embed ecological restoration projects. What is required is innovation in landscape ecological design (Nassauer and Opdam 2008), landscape governance and management (Bohnet and Konold 2015) and a return to our cultural strengths (Hashimoto et al. 2014). These give purpose, and direction to our discussions about sustainable landscapes, in order to overcome the forces that lead to the homogenisation of our social and ecological imaginary.

Acknowledgments The guest editors would like to thank the anonymous referees who added to the quality of the work reflected in this issue. We are appreciative of all the contributors attention to the reviews and to our editorial comment. Finally, we would like to thank editorial staff at sustainable science, especially Ms. Shruti Lahoti for her support and patience.

\section{References}

Angelstam P, Elbakidze M, Axelsson R, Koch NE, Tyupenko TI, Mariev AN, Myhrman L (2013) Knowledge production and learning for sustainable landscapes: forewords by the researchers and stakeholders. Ambio 42:111-115

Antrop M (2005) Why landscapes of the past are important for the future. Landsc Urban Plan 70:21-34

Antrop M (2006) From holistic landscape synthesis to transdisciplinary landscape management. In: Tress B, Tress G, Fry G, Opdam P (eds) From landscape research to landscape planning. Aspects of integration, education and application. Springer, Dordrecht, pp 27-50

Beilin R, Bohnet IC (2015) Culture-production-place and nature: the landscapes of somewhere. Sustain Sci. doi:10.1007/s11625-0150289-5

Beilin R, Sysak T, Hill S (2012) Farmers and perverse outcomes: the quest for food and energy security, emissions reduction and climate adaptation. Glob Environ Change Hum Policy Dimens 22:463-471

Beilin R, Reichelt NT, King BJ, Long A, Cam S (2013) Transition landscapes and social networks: examining on-ground community resilience and its implications for policy settings in multiscalar systems. Ecol Soc 18(2):30. http://dx.doi.org/10. 5751/ES-05360-180230

Beilin R, Lindborg R, Stenseke M, Pereira HM, Llausas A, Slatmo E, Cerqueira Y, Navarro L, Rodrigues P, Reichelt N, Munro N, Queiroz C (2014) Analysing how drivers of agricultural land abandonment affect biodiversity and cultural landscapes using case studies from Scandinavia, Iberia and Oceania. Land Use Policy 36:60-72

Bohnet I (2008) Assessing retrospective and prospective landscape change through the development of social profiles of landholders: a tool for improving land use planning and policy formulation. Landsc Urban Plan 88:1-11

Bohnet IC (2010) Integrating social and ecological knowledge for planning sustainable land- and sea-scapes: experiences from the Great Barrier Reef region, Australia. Landsc Ecol 25:1201-1218

Bohnet IC, Konold W (2015) New approaches to support implementation of nature conservation, landscape management and cultural landscape development; experiences from Germany's southwest. Sustain Sci. doi:10.1007/s11625-015-0290-z

Bohnet I, Smith DM (2007) Planning future landscapes in the wet tropics of Australia: a social-ecological framework. Landsc Urban Plan 80:137-152

Bohnet IC, Gooch M, Hickey R (2010) Young people envision the future of their local area: an explorative study from the Wet Tropics, Australia. Appl Environ Educ Commun 9(3):185-197. http://dx.doi.org/10.1080/1533015X.2010.510027

Bohnet IC, Roberts B, Harding E, Haug KJ (2011a) A typology of graziers to inform a more targeted approach for developing natural resource management policies and agricultural extension programs. Land Use Policy 28:629-637

Bohnet IC, Roebeling PC, Williams KJ, Holzworth D, van Grieken ME, Pert PL, Kroon FJ, Westcott DA, Brodie J (2011b) Landscapes toolkit: an integrated modelling framework to assist stakeholders in exploring options for sustainable landscape development. Landsc Ecol 26:1179-1198

Capra F, Luisi PL (2014) The systems view of life: a unifying vision. Cambridge University Press, Cambridge

Carolan MS (2013) The wild side of agro-food studies: on coexperimentation, politics, change, and hope. Sociologia Ruralis $53: 413-431$

Carolan M (2014) Affective sustainable landscapes and care ecologies: getting a real feel for alternative food communities. Sustain Sci. doi:10.1007/s11625-014-0280-6

Christensen J, Gaire K (2014) Understanding sustainable landscapes through the lens of apple growing: cases of Jumla, Nepal and Harcourt, victoria. Sustain Sci. doi:10.1007/s11625-014-0273-5

Clapp J (2014) Distant agricultural landscapes. Sustain Sci. doi:10. 1007/s11625-014-0278-0

Dramstad WE, Fjellstad WJ (2011) Landscapes: bridging the gaps between science, policy and people. Landsc Urban Plan 100:330-332

Dramstad WE, Fjellstad WJ (2013) 25 years into "our common future": are we heading in the right direction? Landsc Ecol 28:1039-1045

Estrada-Carmona N, Hart AK, DeClerck FAJ, Harvey CA, Milder JC (2014) Integrated landscape management for agriculture, rural livelihoods, and ecosystem conservation: an assessment of experience from Latin America and the Caribbean. Landsc Urban Plan 129:1-11

Fielke SJ, Bardsley DK (2014) Regional agricultural governance in peri-urban and rural South Australia: strategies to improve multifunctionality. Sustain Sci. doi:10.1007/s11625-014-0272-6

Fischer J, Lindenmayer DB, Manning AD (2006) Biodiversity, ecosystem function, and resilience: ten guiding principles for commodity production landscapes. Front Ecol Environ 4:80-86 
Fischer J, Manning AD, Steffen W, Rose DB, Daniell K, Felton A, Garnett S, Gilna B, Heinsohn R, Lindenmayer DB, MacDonald B, Mills F, Newell B, Reid J, Robin L, Sherren K, Wade A (2007) Mind the sustainability gap. Trends Ecol Evol 22:621-624

Foley JA (2011) Can we feed the world and sustain the planet? Sci Am 305:60-65

Folke C (2006) Resilience: the emergence of a perspective for socialecological systems analyses. Glob Environ Change Hum Policy Dimens 16:253-267

Hashimoto S, Nakamura S, Saito O, Kohsaka R, Kamiyama C, Tomiyoshi M, Kishioka T (2014) Mapping and characterizing ecosystem services of social-ecological production landscapes: case study of Noto, Japan. Sustain Sci. doi:10.1007/s11625-0140285-1

Hill R, Miller C, Newell B, Dunlop M, Gordon IJ (2015) Why biodiversity declines as protected areas increase: the effect of the power of governance regimes on sustainable landscapes. Sustain Sci. doi:10.1007/s11625-015-0288-6

Hunt L (2014) The challenge of economic growth for sustainable production landscapes. Sustain Sci. doi:10.1007/s11625-0140276-2

Kasemir B, Jaeger J, Jaeger CC, Gardner MT (2003) Public participation in sustainability science-a handbook. Cambridge University Press, Cambridge

Kauffman J, Arico S (2014) New directions in sustainability science: promoting integration and cooperation. Sustain Sci 9:413-418

Lang DJ, Wiek A, Bergmann M, Stauffacher M, Martens P, Moll P, Swilling M, Thomas CJ (2012) Transdisciplinary research in sustainability science: practice, principles, and challenges. Sustain Sci 7:25-43

Lindenmayer D, Hobbs RJ, Montague-Drake R, Alexandra J, Bennett A, Burgman M, Cale P, Calhoun A, Cramer V, Cullen P, Driscoll D, Fahrig L, Fischer J, Franklin J, Haila Y, Hunter M, Gibbons P, Lake S, Luck G, MacGregor C, McIntyre S, Mac Nally R, Manning A, Miller J, Mooney H, Noss R, Possingham HP, Saunders D, Schmiegelow F, Scott M, Simberloff D, Sisk T, Tabor G, Walker B, Wiens J, Woinarski J, Zavaleta E (2008) A checklist for ecological management of landscapes for conservation. Ecol Lett 11:78-91

Marsden T, Farioli F (2015) Natural powers: from the bio-economy to the eco-economy and sustainable place-making. Sustain Sci. doi:10.1007/s11625-014-0287-z

Milder JC, Hart AK, Dobie P, Minai J, Zaleski C (2014) Integrated landscape initiatives for African agriculture, development, and conservation: a region-wide assessment. World Dev 54:68-80

Millennium Ecosystem Assessment (MEA) (2005) Ecosystems and human well-being: synthesis. Island Press, Washington, D.C

Miller TR (2013) Constructing sustainability science: emerging perspectives and research trajectories. Sustain Sci 8:279-293

Miller TR, Wiek A, Sarewitz D, Robinson J, Olsson L, Kriebel D, Loorbach D (2014) The future of sustainability science: a solutions-oriented research agenda. Sustain Sci 9:239-246

Musacchio LR (2009) The scientific basis for the design of landscape sustainability: a conceptual framework for translational landscape research and practice of designed landscapes and the six Es of landscape sustainability. Landsc Ecol 24:993-1013
Musacchio LR (2013) Key concepts and research priorities for landscape sustainability. Landsc Ecol 28:995-998

Nassauer JI (2012) Landscape as medium and method for synthesis in urban ecological design. Landsc Urban Plan 106:221-229

Nassauer JI, Opdam P (2008) Design in science: extending the landscape ecology paradigm. Landsc Ecol 23:633-644

Parker C (2014) Strawberry fields forever: can consumers see pesticides and sustainability as an issue? Sustain Sci. doi:10. 1007/s11625-014-0267-3

Pearson DM, McAlpine CA (2010) Landscape ecology: an integrated science for sustainability in a changing world. Landsc Ecol 25:1151-1154

Pedroli B (ed) (2000) Lebensraum Landschaft—Landscape our home. Indigo, Zeist-Freies Geistesleben, Stuttgart

Potschin MB, Haines-Young RH (2006) Landscapes and sustainability. Landsc Urban Plan 75:155-161

Santhanam-Martin M, Ayre M, Nettle R (2014) Community sustainability and agricultural landscape change: insights into the durability and vulnerability of the productivist regime. Sustain Sci. doi:10.1007/s11625-014-0268-2

Sayer J, Sunderland T, Ghazoul J, Pfund JL, Sheil D, Meijaard E, Venter M, Boedhihartono AK, Day M, Garcia C, van Oosten C, Buck LE (2013) Ten principles for a landscape approach to reconciling agriculture, conservation, and other competing land uses. Proc Natl Acad Sci USA 110:8349-8356

Sayer J, Margules C, Boedhihartono AK, Dale A Sunderland T, Supriatna J, Saryanthi R (2014) Landscape approaches; what are the pre-conditions for success? Sustain Sci. doi:10.1007/s11625014-0281-5

Schaar JH (1981) Legitimacy of the modern state. Transactions Books, New Brunswick, USA

Scherr SJ, McNeely JA (2008) Biodiversity conservation and agricultural sustainability: towards a new paradigm of 'ecoagriculture' landscapes. Philos Trans R Soc B Biol Sci 363:477-494

Swanwick C, Consultants LU (2002) landscape character assessment-guidance for England and Scotland. The Countryside Agency and Scottish Natural Heritage, Wetherby, Edinburgh

Tress B, Tress G, Decamps H, d'Hauteserre AM (2001) Bridging human and natural sciences in landscape research. Landsc Urban Plan 57:137-141

Tress B, Tress G, Van der Valk A, Fry G (2003) Interdisciplinary and transdisciplinary landscape studies: potential and limitations, Wageningen

Van Paassen A, Van den Berg J, Steingrover E, Werkman R, Pedroli B (2011) Knowledge in action-the search for collaborative research for sustainable landscape development. Wageningen Academic Publishers, Netherlands

Wascher D (2000) Proceedings of European workshop on landscape assessment as a policy tool. European Centre for nature Conservation and The Countryside Agency, Tilburg

WCED (1987) Our common future, Oxford

Wu JG (2013) Landscape sustainability science: ecosystem services and human well-being in changing landscapes. Landsc Ecol 28:999-1023 